\section{Mord am Mainufer}

Film ab: Professor Thomas J. Vogl ermittelt im „Tatort Radiologie“ in seinem bisher härtesten Fall: Am Frankfurter Mainufer hat sich in der Nähe des Klinikums der Johann Wolfgang Goethe-Universität ein Mord zugetragen, bei dessen Aufklärung forensisch-radiologisches Geschick und Teamarbeit gefragt sind. Können Professor Thomas J. Vogl und Joe Bausch den Fall lösen? Finden Sie es auf

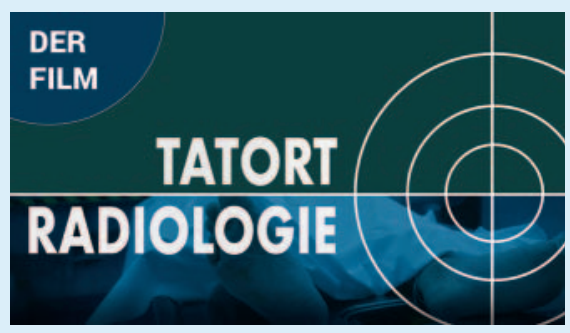

dem YouTbe-Kanal der Deutschen Röntgengesellschaft heraus!

Sie möchten mehr über die forensische Radiologie erfahren? Dann schauen Sie mal auf der Webseite unserer AG ForensischRadiologische Bildgebung vorbei:

www.ag-frb.drg.de 